12 Rackzowski D, Kalat JW, Nebes R. Reliability and validity of some handedness items. Neuropsychologia 1974;12:43-7.

13 Frankenburg WK, Dodds JB. The Denver developmental screening test. f Pediatr 1967;71:181-91.

14 Gillberg IC. Deficits in attention, motor control and perception: follow-up from preschool to the early teens. Uppsala: Uppsala University, 1987.

15 Rasmussen P, Gillberg C. Perceptual, motor and attentional deficits in sevenyear-old children. Acta Paediatr Scand 1983;72:125-30.

16 SPSS. Statistical package for the social sciences. SPSSX advanced statistics guide. Chicago, Illinois: SPSS, 1985.

17 Kleinbaum DG, Kupper LL, Morgenstern H. Epidemiologic research principles and quantitative methods. New York: Van Nostrand Reinhold, 1982

18 Rothman KJ. Modern epidemiology. Boston: Little Brown, 1986

19 Stark CR, Orleans M, Haverkamp AD, Murphy J. Short- and long term risk after exposure to diagnostic ultrasound in utero. Obstet Gynecol 1984;63 $194-200$
20 Scheidt PC, Stanley F, Bryla DA. One-year follow-up of infants exposed to ultrasound in utero. Am 7 Obstet Gynecol 1978;131:743-8.

21 Salvesen $\mathrm{KA}$, Eik-Nes SH. Bruk av fosterlydsdetektor i allmennpraksis. Tidsskr Nor Laegeforen 1990;110:1506-8.

22 AIUM Bioeffects Committee. Bioeffects considerations for the safety of diagnostic ultrasound. I Ultrasound Med 1988;7:1-38.

23 Bishop DVM. Handedness and developmental disorders. Clinics in Developmental Medicine 110. Oxford: Blackwell Scientific and Philadelphia: JB Lippincot 1990

24 Waldenström U, Axelsson O, Nilsson S, Eklund G, Fall O, Lindeberg S, et al Effects of routine one-stage ultrasound screening in pregnancy: randomised controlled trial. Lancet 1988 ;ii:585-8.

25 Saari-Kemppainen A, Karjalainen O, Ylöstalo P, Heinonen OP. Ultrasound screening and perinatal mortality: controlled trial of systemic one-stage screening in pregnancy. Lancet 1990;336:387-9

(Accepted 11 May 1993)

\title{
Case-control study of congenital anomalies in children of cancer patients
}

\author{
L Dodds, L D Marrett, D J Tomkins, B Green, G Sherman
}

University of Toronto, Department of Preventive Medicine and Biostatistics, Toronto, Ontario M5S 1 A8 L Dodds, epidemiologist L D Marrett, associate professor

McMaster University, Department of Pediatrics, Hamilton, Ontario L8N $3 Z 5$

D J Tomkins, associate professor

\section{Ontario Cancer}

Treatment and Research

Foundation, Toronto,

Ontario M4H 1 A8

B Green, programme analyst

Health and Welfare

Canada, Laboratory Centre

for Disease Control,

Ottawa, Ontario K1A 0L2

G Sherman, epidemiologist

Correspondence to:

Dr L Dodds, Reproductive

Care Program, Grace

Maternity Hospital, 5980

University Avenue, Halifax,

Nova Scotia, Canada

B3H 4N1.

BMF 1993;307:164-8
Abstract

Objectives-To determine whether the offspring of cancer survivors are at an increased risk of congenital anomalies and whether cancer therapy before conception is associated with such an increase.

Design-Case-control study using computerised record linkage.

Setting-Ontario, Canada.

Subjects-Parents of children born during April 1979 to December 1986 who had a congenital anomaly diagnosed within the first year of life $(45200$ mothers and 41158 fathers) and a matched sample of parents whose children did not have a congenital anomaly (45 200 mothers and 41158 fathers).

Main outcome measures-Cancer diagnosed in either parent before conception and radiotherapy to the pelvis or abdomen or chemotherapy with an alkylating agent.

Results-Among the mothers, 54 cases and 52 controls were identified as having had cancer diagnosed in Ontario (relative risk $=1 \cdot 04,95 \%$ confidence interval 0.7 to 1.5 ) and among the fathers, 61 cases and 65 controls were identified $(0.9,0.7$ to $1 \cdot 4)$. No significant associations were found between congenital anomalies in the offspring and any type of cancer treatment in either the mothers or the fathers.

Conclusions-The risk of congenital anomalies among liveborn offspring whose parents have had cancer or been treated for cancer is not higher than that in the general population.

\section{Introduction}

The survival rate for children and young adults with cancer have improved substantially over the past few decades $^{12}$ largely because of advances in treatment. In the 1970s, chemotherapeutic drugs used in combination were shown to increase complete remission rates. Thus, many children or young adults treated for cancer in the past $10-15$ years will have received multiple chemotherapeutic drugs, possibly in addition to radiotherapy. ${ }^{3}$ Because much of the treatment is known to be mutagenic and is designed to interfere with the DNA and normal cellular function, there may be adverse effects on reproduction.

Although some animal studies support the relation between radiation and chemical exposure and abnormalities in the offspring, ${ }^{46}$ evidence in humans is inconclusive. The higher rates of adverse reproductive outcomes, including congenital anomalies, found among mothers treated with radiotherapy before con- ception are thought to be primarily due to radiation induced uterine damage rather than to germ cell mutations. ${ }^{7-9}$ Although most studies have not found an association between cancer therapy and congenital anomalies in the offspring, ${ }^{70-11}$ the power to detect moderate increases in risks has generally been limited and few have looked specifically at conditions that might be expected to result from a therapy induced germ cell mutation.

We conducted a case-control study to determine the association between congenital anomalies in the children of those who had cancer diagnosed or treated before conception. We also examined the risks associated with specific cancer therapies and the risks of specific anomalies that could be produced by a new mutation.

\section{Subjects and methods}

The figure summarises the methods used in the study. Cases were defined as the parents of children who were recorded in the database of the Canadian

\section{Identification of children in Ontario with a congenital anomaly diagnosed before age I, from \\ Canadian congenital anomalies surveillance system

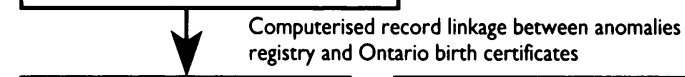

Cases: parents of children with a congenital anomaly identified from child's birth certificate

Controls: parents of children without a congenital anomaly selected from birth certificate file

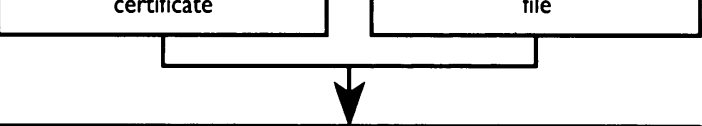

Additional identifying data on parents abstracted from original birth certificates and added to case-control file

Computerised record linkage Cotween case-control file and Ontario cancer registry

Case and control parents with a diagnosis of cancer identified from Ontario cancer registry

Treatment data abstracted from medical records of cases and controls identified in cancer registry

Design of study 
congenital anomalies surveillance system. This database includes children with congenital anomalies diagnosed at birth or cited as a reason for admission to hospital within the first year of life. Children also had to meet the following eligibility criteria: live born in Ontario during 1 April 1979 and 31 December 1986; one or more diagnosis of congenital anomaly according to the ninth revision of the International Classification of Diseases (ICD 740.0-759.9) ${ }^{12}$; and mother a resident of Ontario at the time of the child's birth. A total of 50032 children were eligible, reflecting a rate of congenital anomaly of about $5 \%$ of the total births in Ontario during this period.

Information on the parents of these children was retrieved from birth certificates by computerised linkage with the Ontario birth file. By using the generalised iterative record linkage system, ${ }^{13}$ followed by abstraction from paper files we found a birth certificate for $97 \%$ of the records in the anomaly database.

For each set of case parents, one set of control parents was randomly selected from the Ontario birth file. Parents were matched for year of birth of the child, birth order of the child (first birth, second to third, and fourth or greater), exact maternal age, marital status of the mother (single versus not single), and birthplace of each parent (born in Ontario versus not born in Ontario). Some of these matching variables were selected to ensure that cases and controls would have an equal likelihood of linking to the Ontario cancer registry, if they had had cancer. For example, a parent who had had cancer may be more likely to be in the Ontario cancer registry if born in Ontario than a parent not born in Ontario. Identifiers were abstracted from paper copies of the certificates, as for case parents.

Only information from the earliest selected birth was included in the study, regardless of whether the parent was a case or control at this time to avoid nonindependence affecting the results. Parents who were resident outside Ontario at the time of the index child's birth and those who were adoptive parents were also excluded. This left 45200 case mothers and 41158 case fathers and their matched controls in the study file. Mothers outnumbered fathers because the father was not always named on the birth certificate when the mother was unmarried.

The generalised iterative record linkage system was used to link the study file to the Ontario cancer registry to identify parents who had had cancer diagnosed before the index birth. The Ontario cancer registry contains data on all patients with malignant tumours (except non-melanoma skin cancer) diagnosed in Ontario since 1964. Sample size calculations predicted that, under the null hypothesis, about 300 parents would link to the cancer registry. This estimate accounted for the reduced fertility expected among cancer patients ${ }^{14}$ and the possibility of emigration out of Ontario after cancer was diagnosed.

Only parents with cancer diagnosed before the date of conception, estimated from the date of birth and length of gestation reported on the birth certificate, were included. Initially, 316 possible links to the cancer registry were identified. Medical records of these 316 parents were reviewed to establish both the link to the cancer registry and the diagnosis of cancer. Linkage was confirmed for 233 parents. Although four of these had no medical records available, the quality of agreement on the identifying variables was good.

We collected data on cancer treatment from treatment centres, hospital records, and physicians' offices for all 233 parents with definite links to the registry. Information on radiotherapy included dates (starting and stopping) of each course of therapy, type of radiotherapy, and site of radiotherapy (pelvic or abdominal area versus other areas). For radiotherapy to the pelvic or abdominal area, type of machine, and dose were noted. We also noted name, starting and stopping dates, and dose for each chemotherapeutic drug. Data were also collected on pelvic surgery.

The alkylating agents (cyclophosphamide, melphalan, and mustine) were analysed together because they are thought to have the greatest mutagenic potential; procarbazine was included with these because of its similar mode of action. ${ }^{15}$ An alkylator score was calculated to summarise subjects' exposure. For each alkylating agent received a score of one or two was assigned, depending on whether the dose was in the lower or upper $50 \%$ of the total distribution of doses (a score of 0 was given to those who did not receive that drug). These scores were summed across drugs and subjects with scores in the top $50 \%$ were considered to be in the high dose group. This scoring system assumes that each alkylating agent has the same mutagenic potential and that effects are additive.

Subjects who had received cobalt-60 radiotherapy to the pelvis or abdomen (most subjects who received radiotherapy had been treated with cobalt-60) were also divided into groups. The high dose group comprised subjects whose total dose of cobalt -60 was above the median dose for all subjects treated with radiation.

The results were also examined according to type of congenital abnormality. Congenital anomalies were divided on the basis of ICD code groupings. A child with anomalies in more than one subgroup could, therefore, contribute to several different subgroups. Subgroups were also created according to aetiology ${ }^{16}$ : single gene disorders (autosomal dominant disorders, autosomal recessive disorders, and X linked disorders); chromosomal disorders (autosomal and $\mathrm{X}$ chromosomal disorders); multifactorial disorders; suspected genetic disorders with an unknown aetiology; and anomalies with unknown aetiology. A hierarchical approach was taken so that a child with more than one anomaly contributed to only one subgroup (the order of the hierarchy was as listed above). Classification into aetiological groups was done by DJT based on the fourdigit ICD codes without knowing whether the affected child was the offspring of a cancer patient. Because the single gene disorders are thought to comprise anomalies which might be expressed in the offspring as a result of a new mutation, ${ }^{16}$ this grouping of anomalies may be more sensitive in detecting an effect of an environmental mutagen.

The mothers and fathers were analysed separately because of the possibility of different effects of cancer therapy on the germ cells. Descriptive analyses were done by using the computer program SAS. ${ }^{17}$ Relative risks were approximated by odds ratios which, along with their confidence intervals, were calculated with the EGRET statististical software package. ${ }^{18}$ Estimates of relative risk were based on case-control pairs that were discordant with respect to a previous diagnosis of cancer and cancer treatment. ${ }^{19}$ Because the numbers of discordant pairs were small, exact methods were used to calculate confidence intervals. ${ }^{20}$

\section{Results}

\section{MOTHERS}

For both the case and control mothers, the mean age at the time of the child's birth was 26.7 years; $12 \%$ (5337 cases and 5303 controls) were unmarried, 32\% (14302 cases and 14320 controls) were born outside of Ontario, and 49\% (21989 cases and 22011 controls) were nulliparous before the index birth. Fifty four case mothers and 52 control mothers were identified in the Ontario cancer registry as having had cancer (relative risk $=1 \cdot 04,95 \%$ confidence interval $=0 \cdot 7-1 \cdot 5)$. The most common types of cancer among these 106 mothers were melanoma, thyroid cancer, and breast cancer. 
The mean age at diagnosis of cancer was similar among the cases (23.1 years) and controls ( 23.6 years). The relative risk of anomalies in the offspring decreased with increasing age at diagnosis of cancer, although none was significantly different from unity (relative risk $=1.4,1.0$, and 0.7 for mothers under 20,20 to 29 , and over 29 years at the time of diagnosis).

Table I shows the relative risks and $95 \%$ confidence intervals associated with cancer treatment. The risk for each category reflects any treatment within that category, regardless of other types of treatment which may have been given. No significant change in risk was seen for any category of treatment. We could not look at the dose effect because of the small number of mothers treated with radiotherapy or chemotherapy.

TABLE I-Numbers of case and control mothers and relative risks for congenital anomalies in the offspring by cancer treatment

\begin{tabular}{lcccc}
\hline & $\begin{array}{c}\text { No of } \\
\text { discordant pairs: } \\
\text { case exposed, } \\
\text { control not exposed }\end{array}$ & $\begin{array}{c}\text { No of } \\
\text { discordant pairs: } \\
\text { case not exposed, } \\
\text { control exposed }\end{array}$ & $\begin{array}{c}\text { Relative } \\
\text { risk }\end{array}$ & $\begin{array}{c}95 \% \\
\text { Confidence } \\
\text { interval }\end{array}$ \\
\hline Any radiotherapy & 14 & 19 & 0.7 & 0.3 to 1.6 \\
Any chemotherapy & 6 & 10 & 0.6 & 0.2 to 1.8 \\
Surgery only & 35 & 27 & 1.3 & 0.8 to $2 \cdot 2$ \\
Radiotherapy to pelvis & 4 & 3 & 1.3 & $0 \cdot 2$ to $9 \cdot 1$ \\
Chemotherapy with an alkylating agent & 2 & 6 & 0.3 & 0.0 to 1.9 \\
\hline
\end{tabular}

TABLE II-Numbers of case and control mothers who had had cancer and relative risks for specified congenital anomalies in the offspring

\begin{tabular}{|c|c|c|c|c|}
\hline Anomaly group & $\begin{array}{l}\text { No of } \\
\text { discordant pairs: } \\
\text { case cancer, } \\
\text { control no cancer }\end{array}$ & $\begin{array}{l}\text { No of } \\
\text { discordant pairs: } \\
\text { case no cancer, } \\
\text { control cancer }\end{array}$ & $\begin{array}{l}\text { Relative } \\
\text { risk }\end{array}$ & $\begin{array}{l}95 \% \\
\text { Confidence } \\
\text { interval }\end{array}$ \\
\hline \multicolumn{5}{|l|}{$\begin{array}{l}\text { According to ICD } 9 \text { Code: } \\
\text { Heart and circulatory system }\end{array}$} \\
\hline & 14 & 9 & 1.6 & 0.6 to 4.1 \\
\hline Genital organs (ICD: 752) & 8 & 4 & $2 \cdot 0$ & 0.5 to $9 \cdot 1$ \\
\hline Musculoskeletal deformities (ICD: 754) & 10 & 12 & 0.8 & $0 \cdot 3$ to $2 \cdot 1$ \\
\hline $\begin{array}{l}\text { Other anomalies of limbs and } \\
\text { musculoskeletal anomalies } \\
\text { (ICD: 755-756) }\end{array}$ & & & & \\
\hline \multicolumn{5}{|l|}{ According to aetiology: } \\
\hline Single gene disorder & 4 & 2 & $2 \cdot 0$ & $0 \cdot 3$ to $22 \cdot 0$ \\
\hline Chromosome disorder & 2 & 1 & $2 \cdot 0$ & $0 \cdot 1$ to 118.0 \\
\hline Multifactorial aetiology & 26 & 21 & $1 \cdot 2$ & $0 \cdot 7$ to $2 \cdot 3$ \\
\hline Genetic, unknown aetiology & 6 & 9 & 0.7 & $0 \cdot 2$ to $2 \cdot 1$ \\
\hline Unknown aetiology & 16 & 19 & 0.8 & 0.4 to 1.7 \\
\hline
\end{tabular}

TABLE III-Numbers of case and control fathers and relative risks for congenital anomalies in the offspring by cancer treatment

\begin{tabular}{lcccc}
\hline Cancer treatment & $\begin{array}{c}\text { No of } \\
\text { discordant pairs: } \\
\text { case exposed, } \\
\text { control not exposed }\end{array}$ & $\begin{array}{c}\text { No of } \\
\text { discordant pairs: } \\
\text { case not exposed, } \\
\text { control exposed }\end{array}$ & $\begin{array}{c}\text { Relative } \\
\text { risk }\end{array}$ & $\begin{array}{c}95 \% \\
\text { Confidence } \\
\text { interval }\end{array}$ \\
\hline Any radiotherapy & 20 & 31 & $0 \cdot 7$ & $0 \cdot 4$ to $1 \cdot 2$ \\
Any chemotherapy & 17 & 14 & $1 \cdot 2$ & $0 \cdot 6$ to $2 \cdot 7$ \\
Surgery only & 32 & 29 & $1 \cdot 1$ & $0 \cdot 7$ to $1 \cdot 9$ \\
Radiotherapy to pelvis & 8 & 13 & $0 \cdot 6$ & $0 \cdot 2$ to $1 \cdot 6$ \\
Chemotherapy with an alkylating agent & 11 & 10 & $1 \cdot 1$ & $0 \cdot 4$ to $2 \cdot 9$ \\
\hline
\end{tabular}

TABLE IV-Numbers of case and control fathers with a previous cancer diagnosis and relative risks of specified congenital anomalies in the offspring

\begin{tabular}{|c|c|c|c|c|}
\hline Anomaly group & $\begin{array}{l}\text { No of } \\
\text { discordant pairs: } \\
\text { case cancer, } \\
\text { control no cancer }\end{array}$ & $\begin{array}{c}\text { No of } \\
\text { discordant pairs: } \\
\text { case no cancer, } \\
\text { control cancer }\end{array}$ & $\begin{array}{l}\text { Relative } \\
\text { risk }\end{array}$ & $\begin{array}{c}95 \% \\
\text { Confidence } \\
\text { interval }\end{array}$ \\
\hline \multicolumn{5}{|l|}{ According to ICD 9 Code: } \\
\hline $\begin{array}{l}\text { Heart and circulatory system } \\
\text { (ICD: } 745-747)\end{array}$ & 19 & 13 & 1.5 & 0.7 to $3 \cdot 2$ \\
\hline Genital organs (ICD: 752) & 7 & 15 & 0.5 & $0 \cdot 2$ to $1 \cdot 2$ \\
\hline Musculoskeletal deformities (ICD: 754) & 11 & 13 & 0.9 & $0 \cdot 3$ to $2 \cdot 1$ \\
\hline $\begin{array}{l}\text { Other anomalies of limbs and } \\
\text { musculoskeletal anomalies }\end{array}$ & & & & \\
\hline (ICD: 755-756) & 12 & 8 & 1.5 & $0 \cdot 6$ to $4 \cdot 2$ \\
\hline \multicolumn{5}{|l|}{ According to aetiology: } \\
\hline Single gene disorder & 6 & 3 & $2 \cdot 0$ & 0.4 to $12 \cdot 4$ \\
\hline Chromosome disorder & 3 & 3 & $1 \cdot 0$ & 0.1 to $7 \cdot 5$ \\
\hline Multifactorial aetiology & 29 & 27 & $1 \cdot 1$ & 0.6 to 1.9 \\
\hline Genetic, unknown aetiology & 3 & 4 & 0.8 & $0 \cdot 1$ to $4 \cdot 4$ \\
\hline Unknown aetiology & 20 & 28 & $0 \cdot 7$ & 0.4 to 1.3 \\
\hline
\end{tabular}

No significant increase in risk was seen in the four ICD anomaly subgroups with the most cases (table II). Results for each subgroup were based on all casecontrol pairs for which the case's child had an anomaly within that subgroup. The relative risks of treatment with either radiotherapy or chemotherapy associated with anomalies of the heart and circulatory system and anomalies of the genital organs were $2 \cdot 0(0.4$ to $18 \cdot 0)$ and $4.0(0.3$ to $7 \cdot 0)$ respectively.

Table II also shows the results of the analyses according to aetiological groupings of anomalies. The number of subjects in the group with single gene disorders was small and therefore, although the risk was increased, the confidence interval was wide. None of the subjects in this subgroup who had had cancer were treated with an alkylating agent or radiotherapy to the pelvis or abdomen.

\section{FATHERS}

Among the fathers, 61 cases and 65 controls were found to have had cancer (relative risk $=0.9,95 \%$ confidence interval 0.7 to 1.4 ). The most common cancers were Hodgkin's disease, testicular cancer, melanoma, and brain cancer. About half of the cases (32) and 29 of the controls had not received chemotherapy or radiotherapy for their cancers. The mean ages at diagnosis were 28.0 years for the cases and 25.4 years for the controls. The risk of a congenital anomaly among the offspring did not decrease with increasing age at diagnosis (relative risk $=0.5,1.0$, and 1.2 for fathers under 20, 20-29 years, and over 29 years at the time of diagnosis). Not enough subjects were diagnosed and treated before the age of puberty (when the germ cells are inactive) to evaluate risk in this subgroup.

The risk associated with the various forms of cancer therapy and anomalies in the offspring did not differ significantly from unity (table III). There was no evidence that the risk of congenital anomalies among the offspring rises with increasing dose of alkylating agents, although the confidence intervals were wide (relative risk $1.2,95 \%$ confidence interval 0.3 to 4.2 for those in the lower dose group and $1 \cdot 0,0.2$ to 5.4 for those in the higher dose group). The risk did not increase with dose of cobalt- 60 radiotherapy directed at the pelvis or abdomen. The relative risk was $0.8(0 \cdot 2$ to 3.7$)$ for those in the low dose group ( $\leqslant 25 \mathrm{~Gy}$ ) and $0.6(0 \cdot 1$ to $2 \cdot 3)$ for those in the high dose group $(>25$ $\mathrm{Gy})$.

No significant increase in relative risk was seen for any of subgroups of anomalies (table IV). Although the increase in risk for those with a single gene disorder was not significant, three of the six case fathers who had had cancer in this subgroup had been treated with an alkylating agent or radiotherapy to the pelvis or abdomen, or both, whereas none of the three controls in this subgroup had received either of these therapies.

\section{Discussion}

Our results are consistent with the previous epidemiological studies designed to investigate the risk of congenital anomalies in children of cancer patients, most of which have found no association. While most of the previous studies have followed cohorts of cancer patients and observed their offspring, we used a casecontrol method and computerised record linkage. The validity of our results depends, in part, on the accuracy with which the record linkage identified cases and controls with a previous cancer diagnosis. Incorrect matches (false positives) or incorrect non-matches (false negatives) in either of the record linkages used in this study could potentially bias the results. 
birth record corresponding to each anomaly record) are unlikely since links were verified with information available on the paper copy of the birth certificate. Likewise, because a birth certificate was found for $97 \%$ of the children in the anomaly database, the false negative rate should be low. A likely reason why birth certificates were not found for the remaining 3\% is that the birth occurred outside Ontario but the child was admitted to hospital in Ontario during the first year of life. Since this group was not eligible for the study, these omissions would not result in bias.

It is more difficult to estimate the number of parents missed in the linkage between the case-control file and the Ontario cancer registry. The number of links among fathers agreed closely with that expected under the null hypothesis. However, slightly fewer mothers than expected were linked to the registry. Some true links for mothers may have been missed because of name changes between diagnosis of cancer and the birth of the child, resulting in them being wrongly classified as not having had cancer. Because identifying information on cases and controls was comparable and the linkage to the cancer registry was done without knowledge of case-control status any misclassification should have affected cases and controls equally. Although misclassification would drive the relative risk towards unity, it is unlikely that misclassification accounted for the lack of effect observed in this study. False positive links to the cancer registry are improbable because nearly all accepted links were confirmed through data found in medical records.

Parents who had cancer diagnosed while resident outside Ontario would not appear in the Ontario cancer registry and therefore would have been incorrectly classified, as not having had cancer. Cases and controls were matched for birth place to minimise the possibility of any such misclassification biasing the results. Among both mothers and fathers, the risks associated with previous cancer and anomalies in their offspring are similar in the subroups of parents born in and outside of Ontario. Thus the relative risks for those born outside of Ontario seem unlikely to be biased because of case-control differences in the likelihood of linking to the cancer registry.

\section{EFFECT OF CANCER TREATMENT}

The treatments most likely to be mutagenic (and therefore to be associated with anomalies in the offspring) are radiotherapy directed at the pelvis and chemotherapy with an alkylating agent. Our results do not suggest that these therapies increase the risk of anomalies in the offspring of either the mothers or the fathers. While this may mean that cancer therapy does not increase the risk of having a child with a congenital anomaly, there are other possible explanations for the observed results.

Firstly, cancer patients who have received potentially mutagenic therapy may be more likely to undergo prenatal screening than those with no history of cancer and may therefore have a higher rate of therapeutic abortion, reducing the number of offspring with anomalies. This would, however, only affect the number of offspring with chromosomal anomalies, as prenatal diagnosis for other genetic disorders was not widely available during the study period. Secondly, the adverse effects of cancer therapy may manifest themselves earlier in the reproductive process-for example, as infertility among those treated most aggressively with potentially mutagenic therapy. ${ }^{14}$ Cancer patients who have liveborn offspring may therefore have received chemotherapy and radiotherapy at relatively low doses with diminished mutagenic potential.

The effect of cancer therapy on sporadic genetic disease has not been conclusively established. Single gene disorders are important indicators of possible germ cell mutations, but occur very rarely. ${ }^{162}$ Several investigators have looked for increased rates of single gene disorders among the offspring of cancer survivors but have not noted any. ${ }^{711}$ The fact that three of the six case fathers and none of the three controls with a previous diagnosis of cancer in this subgroup had been treated with potentially mutagenic cancer therapies supports the possibility of a genetic effect. None of the cases or control mothers in this subgroup were treated with these therapies. These findings are somewhat difficult to interpret because of the small numbers of subjects in this anomaly subgroup. In addition, the grouping of anomalies by aetiology was based on the limited information in the anomaly database, namely the four digit ICD-9 codes for anomalies recorded through the first year of life. Since family histories were not known, some of the anomalies observed in the offspring may have been familial rather than the result of a new mutation. Although the anomalies were assigned to groups by one person who was blinded to parental exposure, the lack of detailed diagnostic and familial information may have resulted in some misclassification of both cases and controls. Given the rarity of single gene disorders and the likelihood that any increase in risk will not be large, many subjects will be needed to conclusively determine the risks associated with cancer therapy and these disorders.

Studies that have examined ICD subgroups of anomalies have not shown consistent associations with any particular subgroup. However, Green et $a t^{2}$ recently reported a possible association between women treated with dactinomycin and cardiac defects among their offspring. We found that relative risks for the subgroup of cardiac anomalies were moderately but not significantly increased in both the mothers and the fathers, although no association was found with dactinomycin.

\section{CONFOUNDING}

Studies that use data collected for other purposes are limited by the information available in the databases. In this study, confounder information comprised that available from birth certificates. We were therefore able to match (and control for) some potential indicators of socioeconomic status (parental age, marital status), although residual confounding with socioeconomic status may exist. Other potential confounders were not available on the birth certificate-for example, smoking, alcohol. Since most of the cases of cancer were diagnosed by early adulthood, it is not unlikely that these factors would be strongly related to the development of cancer. It seems reasonable to assume that few, if any, other factors would be strongly related to both congenital anomalies in the offspring and cancer in a parent. The known advantages of using existing datathat is, the ability to study large numbers of subjects at a relatively low cost-outweighed the possibility of a small amount of bias associated with the lack of information on potential confounding variables.

A recent study of occupational exposure to ionising radiation among fathers and leukaemia in their children suggested that the observed increased risk was due to a cell mutation which was leukaemogenic in the offspring. ${ }^{23}$ The results also suggested that exposure during the six months before conception may be the most relevant. We found no evidence of increased risk among fathers treated with either radiotherapy or an alkylating agent within a year of conception, although the numbers were small. As many cancer patients are advised to wait a year after treatment before conceiving it may be difficult to analyse the risk of anomalies in the offspring among parents who are treated within a year of conception. ${ }^{24}$

Our results should offer some reassurance to people who survive cancer. They suggest that, among live- 


\section{Clinical implications}

- Young adults and children now commonly survive treatment for cancer and subsequently want to have a family

- Many fear that the toxic treatment they received for cancer will affect their children

- This study shows that the risk of having a child with congenital anomalies was not increased among parents who had been treated for cancer

- For live births there was no relation between increasing toxicity of treatment and congenital anomalies

- Cancer patients can be reassured that any liveborn offspring are unlikely to be affected by cancer treatment
3 Balis FM, Holcenberg JS, Poplack DG. General principals of chemotherapy. In: Pizzo AA, Poplack DG, eds. Principals and practice of pediatric oncology. Philadelphia: J B Lippincott, 1989:165-205.

4 Kirk KM, Lyon MF. Induction of congenital anomalies in offspring of female mice exposed to varying doses of X-rays. Mutat Res 1982;106:73-83.

5 Nomura T. X-ray and chemically induced germ-line mutation causing phenotypical anomalies in mice. Mutat Res 1988;198:309-20.

6 Trasler JM, Hales BF, Rabaire B. Paternal cyclophosphamide treatment of rats causes fetal loss and malformations without affecting male fertility. Nature 1985;316:144-6.

7 Hawkins MM. Is there evidence of a therapy-related increase in germ cell mutation among childhood cancer survivors? I Natl Cancer Inst 1991;83 $1643-50$

8 Li FP, Gimbrere K, Gelber RD, Sallan SE, Flamant F, Green DM, et al. Outcome of pregnancy in survivors of Wilm's tumor. JAMA $1987 ; 257^{2}$ 216-9.

9 Hawkins MM, Smith RA. Pregnancy outcomes in childhood cancer survivors: probable effects of abdominal irradiation. Int $\mathcal{f}$ Cancer 1989;43:399-402.

10 Mulvihill JJ, McKeen EA, Rosner F, Zarrabi MH. Pregnancy outcomes in cancer patients. Experience in a large cooperative group. Cancer 1987;60 cancer patien $1143-50$.

11 Mulvihill JJ. Sentinel and other mutational effects in offspring of cancer survivors. Prog Clin Bio Res 1990;340:179-86.

born offspring, the probability of having a child with a congenital anomaly is not appreciably different for those who have had cancer or been treated for cancer from that for the general population.

We acknowledge the help from the staff who worked on this study. We also thank the Office of the Registrar General, Statistics Canada, the Canadian congenital anomalies surveillance system, and the hospitals, regional cancer centres, and the Princess Margaret Hospital for data used in this study. The cooperation of the staff at the Ontario cancer registry and in the information systems division of the Ontario Cancer Treatment and Research Foundation is also appreciated. We thank Dr David Carr for his help in assigning aetiologoical diagnoses to the congenital anomalies. Drs A B Miller and John Frank provided helpful suggestions throughout the study. This study was funded by the Ontario Ministry of Health. LD was supported by a PhD fellowship and DJT by a national health research scholar award from the National Health Research and Development Program of Health and Welfare Canada.

1 Young JL, Ries LG, Silverberg E, Horm JW, Miller RW. Cancer incidence, survival and mortality for children younger than age 15 years. Cancer 1986;58:598-602

2 Hawkins MM. Long term survival and cure after childhood cancer. Arch Dis Child 1989;64:798-807.
12 World Health Organisation. International Classification of Diseases. Geneva: WHO, 1977 .

13 Howe GR, Lindsay J. A generalized iterative record linkage system for use in medical follow-up studies. Comput Biomed Res 1981;14:327-40. et al. Effects of treatment on fertility in long term survivors of childhood or adolescent cancer. $N$ Engl f Med 1987;317:1315-21.

15 Chabner BA, Myers CE. Clinical pharmacology of cancer chemotherapy. In: DeVita VT Jr, Hellman S, Rosenberg SA, eds. Cancer: principals and practice of oncology. Philadelphia: J B Lippincott, 1982:156-97.

16 Baird PA, Anderson TW, Newcombe HB, Lowry RB. Genetic disorders in children and young adults: a population study. Am F Hum Genet 1988;42 children

17 SAS Institute, SAS version 5. Cary, NC: SAS, 1985

18 EGRET Seattle, Washington: Statistics and Epidemiology Research Corporation, 1988.

19 Breslow NE, Day NE. Statistical methods in cancer research. Vol 1. The analysis of case-control studies. Lyon: International Agency for Research on Cancer, 1980. (IARC scientific publication No 32.)

20 Rothman KJ. Modern epidemiology. Toronto: Little, Brown, 1986.

21 Czeizel A. Population surveillance of sentinel anomalies. Mutat Res 1989;212:3-9.

22 Green DM, Zevon MA, Lowrie G, Seigelstein N, Hall B. Congenital anomalies in children of patients who received chemotherapy for cancer in childhood and adolescence. $N$ Engl F Med 1991;325:141-6.

23 Gardner MJ, Snee MP, Hall AJ, Powell CA, Downes S, Terrell JD. Results of case-control study of leukaemia and lymphoma among young people near Sellafield nuclear plant in West Cumbria. BMJ 1990;300:423-9.

24 Blatt J, Bleyer WA. Late effects of childhood cancer and its treatment. In: Pizzo AA, Poplack DG, eds. Principals and practice of pediatric oncology. Philadelphia: J B Lippincott, 1989:1003-25.

(Accepted 11 May 1993)
14 Byrne J, Mulvihill JJ, Myers MH, Connelly RR, Naughton MD, Krauss MR,

\title{
Factors affecting uptake of measles, mumps, and rubella immunisation
}

\author{
Jun Li, Brent Taylor
}

Abstract

Objective-To study factors affecting uptake of measles, mumps, and rubella immunisation.

Design-Cohort study using data from computerised child health systems.

Setting-10 health districts in North East Thames and North West Thames regions.

Subjects - 7841 children born in January to March 1990 and resident in the districts up till the end of October 1991.

Main outcome measures-Overall uptake of measles, mumps, and rubella immunisation, varia-

Department of Community Child Health, Royal Free Hospital School of Medicine, London NW3 2QG

Jun $\mathrm{Li}$, research fellow Brent Taylor, professor of community child health

Correspondence to: Dr Li.

BMf 1993;307:168-71 registered for immunisation (general practitioner or clinic), and one parent family status.

Conclusions-Many districts have difficulties in meeting the $90 \%$ target for measles, mumps, and rubella immunisation, mainly because of the characteristics of their local population. To increase overall coverage, the health service should target families with adverse factors, especially those whose children have missed previous immunisations.

\section{Introduction}

In October 1988 the combined measles, mumps, and rubella vaccine replaced monocomponent measles vaccine in the routine childhood immunisation programme for the United Kingdom.' This change was partly to improve rubella coverage as well as to introduce protection against mumps into the schedule. The change was also hoped to improve uptake of measles immunisation, about which there had been widespread concern in Britain..$^{2-5}$ Coverage with measles, mumps, and rubella vaccine has dramatically increased protection against measles in the country as a whole. ${ }^{6}$ The improved uptake of measles, mumps, and 